\title{
Involvement of Toll-like receptor 2 on human corneal epithelium during an infection of Pythium insidiosum
}

\author{
Patimaporn Wongprompitak, ${ }^{1}$ Nawarat Pleewan, ${ }^{1}$ Wiwit Tantibhedhyangkul, ${ }^{1}$ Angkana Chaiprasert, ${ }^{2}$ Pinnita Prabhasawat, ${ }^{3}$ \\ Naharuthai Inthasin, ${ }^{1}$ Pattama Ekpo ${ }^{1}$
}

\begin{abstract}
Background: Pythium insidiosum, a pathogenic oomycete, is a common causative organism of infectious corneal ulcer. Studying the innate immune response at the ocular surface is important for better understanding of the underlying pathogenesis and host defense against $P$. insidiosum infection.
\end{abstract}

Objective: The present study aims to investigate the role of Toll-like receptor (TLR)2 on human corneal epithelial cells (HCECs) in P. insidiosum infection.

Methods: Human embryonic kidney (HEK) cells were stimulated with either P. insidiosum zoospores or hyphae. NF- $\kappa \mathrm{B}$ activation was determined by spectrophotometric measurement of secreted embryonic alkaline phosphatase (SEAP) levels. The role of TLR2 in P. insidiosum infection was studied in HCECs and monocyte derived macrophages (MDMs) using anti-TLR2 neutralizing antibody. The expression levels of pro-inflammatory cytokines were determined.

Results: Both P. insidiosum hypha and zoospore stimulated TLR2-dependent NF- $\kappa$ B activation in HEK-Blue ${ }^{\mathrm{TN}}-\mathrm{hTLR} 2$ cells in dose-dependent manner. $I L-6$ and $I L-8$, but not $I L-1 \beta$, were upregulated in HCECs after stimulation with $P$. insidiosum. Blockade of TLR2 on HCECs altered neither IL-6 nor IL-8 expressions. In contrast, the 3 cytokines were upregulated in the stimulated MDMs and the expression levels of $I L-1 \beta$ and $I L-8$ but not $I L-6$ were attenuated in TLR2 blockade MDMs.

Conclusion: P. insidiosum was recognized by human TLR2 on HEK cells. The mRNA expression levels of certain cytokines were dependent of TLR2 in P. insidiosum infected MDMs but not HCECs at early stage of infection.

Key words: Toll-like receptor 2, Pythium insidiosum, ocular pythiosis, human corneal epithelium, inflammatory cytokine

From:

${ }^{1}$ Department of Immunology, Faculty of Medicine Siriraj Hospital, Mahidol University, Bangkok, Thailand.

2 Department of Microbiology, Faculty of Medicine Siriraj Hospital, Mahidol University, Bangkok, Thailand.

${ }^{3}$ Department of Ophthalmology, Faculty of Medicine Siriraj Hospital, Mahidol University, Bangkok, Thailand.

\section{Introduction}

Pythium insidiosum is an oomycetes fungus belonging to the kingdom Straminipila. This organism can present in two forms including non-septate mycelium and motile biflagellated zoospores. However, it is not a true fungus because its cell wall composed of cellulose and $\beta$-glucan but not chitin. $P$. insidiosum is the causative agent of pythiosis, which mainly occurs in tropical and subtropical areas. ${ }^{1}$ The fungus is ubiquitous in soils and aquatic environments. The sexual reproduction is oogamy and develops motile biflagellated zoospore

\section{Corresponding author:}

Pattama Ekpo

Department of Immunology, Faculty of Medicine Siriraj Hospital,

Mahidol University, Bangkok, 10700, Thailand

Email: pattama.ekp@mahidol.ac.th

in wet environment. The infection is by direct contact to water containing zoospore. Human pythiosis found mostly in Thailand. There are four different forms of pythiosis which are vascular (59\%), ocular (33\%), cutaneous/subcutaneous (5\%) and disseminated (3\%) forms. ${ }^{1}$ Non-ocular pythiosis usually occurs in patient with blood dyscrasias such as thalassemia. ${ }^{1,2}$ Ocular pythiosis, $P$. insidiosum keratitis, can occur in healthy people resulting in visual loss in approximately $80 \%$ of ocular infection cases. ${ }^{2-4}$ 
The corneal epithelium is outermost part of the eye and constant contact with potentially pathogenic microbes, especially opportunistic fungi that cause fungal keratitis. The role of an immune response at the corneal epithelium is mainly mediated by innate immunity because the cornea is avascular and has limited immune defenses. Pattern recognition receptors (PRRs) are expressed on the corneal epithelium to recognize and response to pathogen associated molecular patterns (PAMPs). ${ }^{5}$ The responsive mechanisms to invasive pathogens include production of pro-inflammatory cytokines, chemokines and antimicrobial peptides as well as recruitment of innate immune cells to the site of infection. ${ }^{5,6}$ However, the mechanism by which the host corneal epithelium can successfully defend against invasive $P$. insidiosum is unknown. Unfortunately, potential virulence factors of $P$. insidiosum as well as immune response against the fungal infection have not been fully elucidated. Thus, the knowledge of the innate immune response of corneal epithelium to $P$. insidiosum infection may provide the better understanding of the protection and pathogenesis of $P$. insidiosum keratitis.

Toll-like receptor (TLR)2 and TLR4 play important roles in fungal recognition and may cause chronic inflammation due to the recruitment of neutrophil to the corneal stoma and resulting in corneal destruction. ${ }^{7}$ However, in acute phase response, local inflammation may induce anti-fungal immune response. Thus, TLR2 and/or TLR4 may be involved in proinflammatory cytokine expressions of human corneal epithelium to $P$. insidiosum infection leads to neutrophil recruitment for fungal clearance and also promote pathogenesis.

The present study aims to study the involvement of TLR2 and TLR4 in recognition of $P$. insidiosum zoospore and hypha and to investigate the role of the TLR on human corneal epithelial cells in P. insidiosum infection.

\section{Methods}

\section{$P$. insidiosum strain and preparation of zoospore and hypha}

P. insidiosum was kindly provided by Assoc. Prof. Angkana Chaiprasert from the Department of Microbiology, Faculty of Medicine Siriraj Hospital, Mahidol University, Thailand. It was isolated from left eye of a 14 years old female $P$. insidiosum keratitis patient. The isolate of $P$. insidiosum was grown on $2 \%$ water agar (BD, NJ, USA) plate and inoculated into sterilized water containing grass blades (Axonopus compresus) and further incubated at $37^{\circ} \mathrm{C}$ for 2 days. The induction of zoospore formation and preparation of hyphae were performed as previously described. ${ }^{8}$ Briefly, for induction of zoospore formation, water was removed, replaced with induction media and incubated at $37^{\circ} \mathrm{C}$ for approximately $3 \mathrm{~h}$. The formation of sporangia and zoospore were observed under light microscopy. Zoospores were harvested by filtrating through sterilized gauze and centrifuged. For preparation of hyphae, zoospores at $10^{6}$ cells were inoculated into Sabouraud's dextrose broth $(\mathrm{SDB})$ and incubated at $25^{\circ} \mathrm{C}$ for $24 \mathrm{~h}$. The harvested zoospores and hyphae were washed with endotoxinfree phosphate buffer saline (PBS). Killed zoospores and hyphae were prepared by adding $0.01 \%$ of Sodium Hypochlorite
( $\mathrm{NaOCl})$ in endotoxin-free PBS and then washed. After washing, hyphae and zoospores were resuspended in the cell culture medium used in the stimulation experiments. Negative controlled zoospore and hypha $(\mathrm{Nc})$ were also prepared by the same processes for preparation of zoospore and hypha without fungal inoculation. Enumeration of zoospores was performed using hemacytometer.

\section{HEK-Blue ${ }^{\mathrm{Tm}}-\mathrm{hTLR}$ cell cultivation and stimulation}

HEK-Blue ${ }^{\text {Tm }}-$ hTLR2, -hTLR4 and their controls (HEK-Blue ${ }^{\mathrm{tm}}$ -Null1 and Null2, respectively) (InvivoGen, CA, USA) were cultured in Dulbecco's Modified Eagle Medium (DMEM) (Life technology, NY, USA) containing $10 \%(\mathrm{v} / \mathrm{v})$ heat-inactivated fetal bovine serum (FBS), $50 \mathrm{U} / \mathrm{ml}$ penicillin, $50 \mu \mathrm{g} / \mathrm{ml}$ streptomycin, and $100 \mu \mathrm{g} / \mathrm{ml}$ normocin ${ }^{\mathrm{mm}}$ (InvivoGen).

The HEK-Blue cells were seeded at a density of $2.8 \times 10^{4}$ cells/well of a flat-bottom 96-well plate. The cells were stimulated with hyphae at multiplicity of infection (m.o.i.) 0.02 , 0.04, 0.09 and 0.17; zoospores at m.o.i. 0.02, 0.04, 0.07 and 0.36 for 20-24 h. After stimulation, supernatant from stimulated cells was collected for determination of NF- $\mathrm{kB}$ activation. Heat killed Listeria monocytogenase (HKLM) and E. coli lipopolysaccharide (LPS) are served as positive control for hTLR2 and hTLR4, respectively. Negative control (Nc) was performed using controlled hyphae or zoospore. For TLR blocking experiment, HEK-Blue cells were pre-incubated with neutralizing antibody or isotype control (InvivoGen) for $1 \mathrm{~h}$ before stimulation with the zoospores or hyphae.

\section{Determination of $\mathrm{NF}-\kappa \mathrm{B}$ activation}

For determination of NF- $\kappa B$ activation, $20 \mu \mathrm{l}$ of supernatant collected from stimulated HEK-Blue cells was transferred to a well of 96-well plate containing $180 \mu \mathrm{l}$ of QUANTI -BlueTM detection medium (InvivoGen). The reaction was incubated for $3 \mathrm{~h}$ and secreted embryonic alkaline phosphatase (SEAP) levels were determined using spectrophotometer at absorbance $630 \mathrm{~nm}$.

\section{Primary human corneal epithelial cell (PHCEC) cultivation}

The limbal tissue was obtained from cadaveric donors provided by the Thai Red Cross Society. This study was approved by Siriraj Institutional Review Board of the Faculty of Medicine Siriraj Hospital, Mahidol University, Thailand (Protocol number: 200/2555(EC3)). The PHCECs were cultured from limbal tissue as previously described. ${ }^{32}$

\section{Human corneal epithelial cell (HCEC) cultivation}

HCECs (ATCC CRL-11516) were cultured in Keratinocyte serum-free medium (K-SFM) supplemented with $5 \mathrm{ng} /$ $\mathrm{ml}$ recombinant human epidermal growth factor, $0.05 \mathrm{mg} / \mathrm{ml}$ bovine pituitary extract, $0.005 \mathrm{mg} / \mathrm{ml}$ insulin, $500 \mathrm{ng} / \mathrm{ml} \mathrm{hy-}$ drocortisone, $50 \mathrm{U} / \mathrm{ml}$ penicillin and $50 \mu \mathrm{g} / \mathrm{ml}$ streptomycin (Invitrogen) in tissue culture flask pre-coated with $0.01 \mathrm{mg} /$ $\mathrm{ml}$ bovine serum albumin (BSA) (SIGMA, St. Louis, MO), 0.01 $\mathrm{mg} / \mathrm{ml}$ fibronectin (Roche, GM, Basel, Switzerland) and 0.03 $\mathrm{mg} / \mathrm{ml}$ bovine collagen type I (SIGMA) at $37^{\circ} \mathrm{C}$ in $5 \% \mathrm{CO}_{2}$ for at least $2 \mathrm{~h}$. 


\section{PHCEC and HCEC stimulations}

PHCECs and HCECs at $2.5 \times 10^{4}$ cells were grown in supplement-free Keratinocyte Basal Medium-2 (LONZA, Basel, Switzerland) in 96-well plate for 2 days. The cells were stimulated with zoospores at m.o.i. 0.0025 and 0.005 for 3-6 h. Control zoospore and $1 \times 10^{8} \mathrm{HKLM}$ were used as negative and positive controls for the cell stimulation, respectively. For TLR2 blocking experiment, HCECs were pre-incubated with neutralizing antibody or isotype control (InvivoGen) for $1 \mathrm{~h}$ before stimulation with the zoospores.

\section{Human monocyte-derived macrophage (MDM) cultivation and stimulation}

Peripheral blood mononuclear cells (PBMCs) were separated from the whole blood of anonymous donor by density gradient centrifugation method using Lymphocyte separation medium (LSM) (Biowest, KC, USA). The experiments were approved by Siriraj Institutional Review Board of the Faculty of Medicine Siriraj Hospital, Mahidol University, Thailand (Protocol number: 200/2555(EC3)).

MDMs were prepared as previously describe. ${ }^{31} \mathrm{MDMs}$ at day 9 were used for stimulation experiment. $3 \times 10^{4} \mathrm{MDMs}$ in 96-well plate were stimulated with live zoospore at m.o.i. of 0.005. Control zoospore and $1 \times 10^{8} \mathrm{HKLM}$ were used as negative and positive controls for the cell stimulation, respectively. For TLR2 blocking experiment, MDMs were pre-incubated with neutralizing antibody or isotype control (InvivoGen) for $1 \mathrm{~h}$ before stimulation with the zoospores.

\section{RNA extraction and cDNA synthesis}

Total RNA was extracted using the RNeasy-Plus Mini kit (QIAGEN Inc., California, USA). The extracted RNA was used as a template for cDNA synthesis using SuperScript ${ }^{\mathrm{Tm}}$ III FirstStrand Synthesis System kit (Invitrogen).

\section{Polymerase chain reaction (PCR)}

Reverse transcription PCR (RT-PCR) was used to determine the expression of TLR1-10 genes in PHCEC. The optical density of PCR products was analyzed by agarose gel electrophoresis. $^{33}$
Quantitative Real time PCR (qRT-PCR) was performed and analyzed using Bio-Rad ${ }^{\circledR}$ CFX96 ${ }^{\mathrm{TM}}$ (Applied Biosystem, CA, USA) with iTaq ${ }^{\text {TM }}$ Universal SYBR ${ }^{\oplus}$ Green Supermix (Bio$\mathrm{Rad}^{\oplus}$, California, USA). PCR was performed following thermal cycling condition: initial denaturation at $95^{\circ} \mathrm{C}$ for $1 \mathrm{~min}$, denaturation at $95^{\circ} \mathrm{C}$ for $10 \mathrm{~s}$, annealing at $59^{\circ} \mathrm{C}$ for $15 \mathrm{~s}$ and extension at $72^{\circ} \mathrm{C}$ for $5 \mathrm{~s}$. Relative expression was normalized with $\mathrm{GAPDH}$ and calculated $\mathrm{ddC}_{\mathrm{T}}$. Primers used for qRT-PCR analysis were listed in Table $\mathbf{1 .}$

\section{Measurement of IL-8 protein expression}

The concentration of human $I L-8$ was measured using Human IL-8 ELISA MAX ${ }^{\mathrm{TM}}$ Standard Sets (BioLegend, San Diego, CA).

\section{Statistical analysis}

Data were expressed as mean \pm SEM of triplicates from 3 independent experiments. Statistical significance of differences between two groups was analyzed by paired-sample $t$-test depending on the contextual format of information. Equality of means among multiple groups was analyzed by One-Way ANOVA using GraphPad Prism (version 3.00). Differences were considered statistically significant at $P<0.05$.

\section{Results}

P. insidiosum induced NF- $\kappa$ B activation on HEK-Blue ${ }^{\mathrm{Tm}}-\mathrm{hTLR2}$ cells

Hyphae and zoospores of $P$. insidiosum significantly induced NF- $\kappa$ B activation on HEK-Blue ${ }^{\mathrm{Tm}}$-hTLR2 in the dose dependent manner when compared with negative control (HEK-Null1 cell activation) (Figure 1). In contrast, the NF- $\kappa \mathrm{B}$ activation was not induced in HEK-Blue ${ }^{\mathrm{Tm}}-$ hTLR4 by both hyphae and zoospores (data not shown).

To determine the requirement of TLR1 or TLR6 in TLR2 recognition, the blockade of TLR1 or TLR6 by specific neutralizing antibodies was performed. The response ratio of HEKBlue ${ }^{\text {TM }}$-hTLR2 cells pre-incubated with anti-TLR2, but not anti-TLR1 and TLR6 neutralizing antibodies, was significantly decreased when compared with the unblocked cells or isotype control (Figure 1). Thus both hypha and zoospore of $P$. insidiosum are mainly recognized by TLR $2 / 2$ homodimers.

Table 1. Primer sequences used for qRT-PCR analysis, their corresponding melting temperatures (Tm) and sizes of PCR products (base pairs).

\begin{tabular}{llcc}
\multicolumn{1}{c}{ Gene } & \multicolumn{1}{c}{ Sequence $\left(5^{\prime} \rightarrow 3^{\prime}\right)$} & Tm $\left({ }^{\circ} \mathbf{C}\right)$ & PCR product $(\mathbf{b p})$ \\
\hline$I L-8 \_F$ & GCCAACACAGAAATTATTGTAAAGCTT & 56 & 112 \\
$I L-8 \_R$ & AATTCTCAGCCCTCTTCAAAAACTT & 55 & \\
$I L-1 \beta \_F$ & TGGAGCAACAAGTGGTGT & 56 & 157 \\
$I L-1 \beta \_R$ & TTGGGATCTACACTCTCCAGC & 58 & \\
$I L-6 \_F$ & CGGGAACGAAAGAGAAGCTCTA & 59 & 68 \\
\hline$L-6 \_R$ & GGCGCTTGTGGAGAAGGAG & 60 & \\
\hline TNF- $\alpha \_F$ & CCCAGGCAGTCAGATCATCTTC & 60 & 75 \\
\hline$T N F-\alpha \_R$ & CAGCTTGAGGGTTTGCTACAAC & 60 & \\
\hline$G A P D H \_F$ & ACAGCCTCAAGATCATCAGCA & 59 & 119 \\
\hline$G A P D H \_R$ & GATGGCATGGACTGTGGTCA & 60 & \\
\hline
\end{tabular}



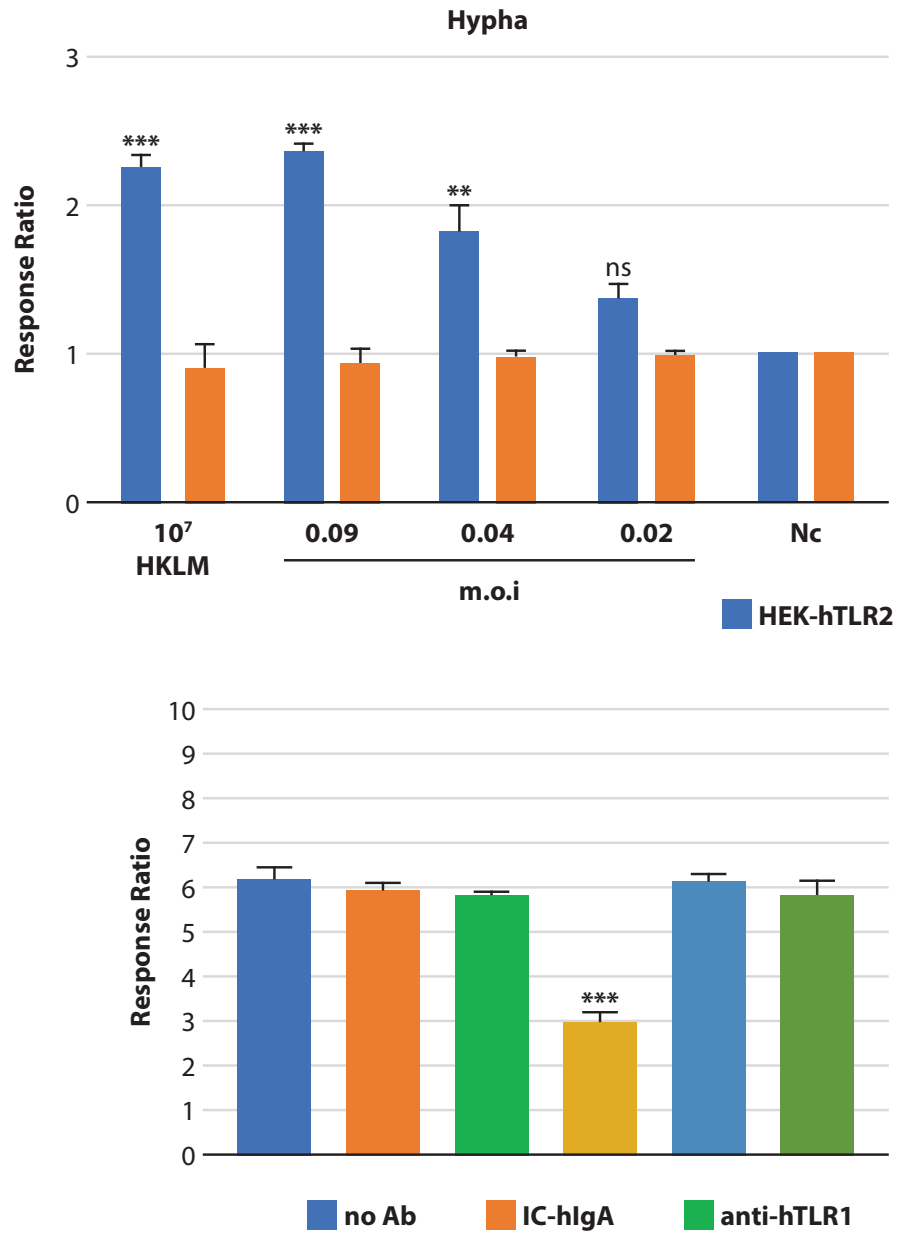

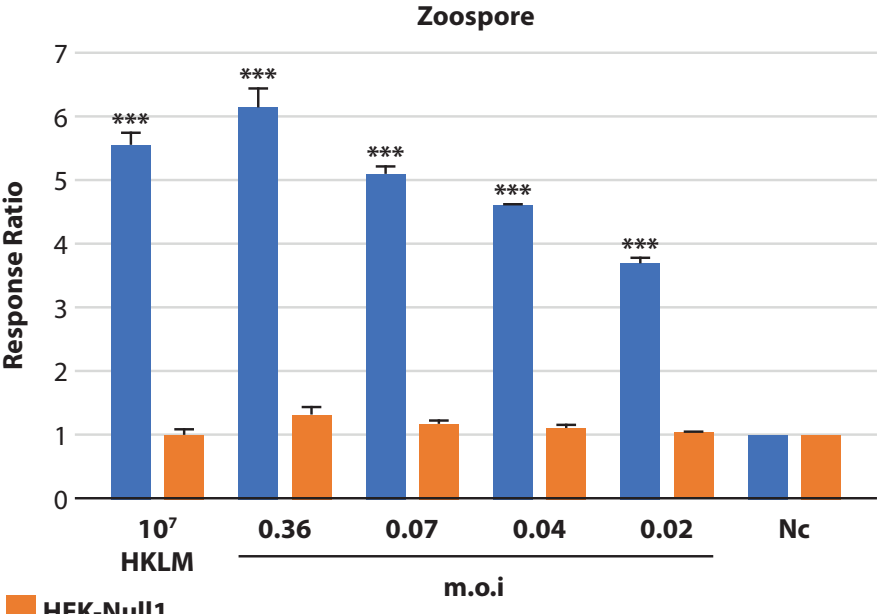

HEK-Null1

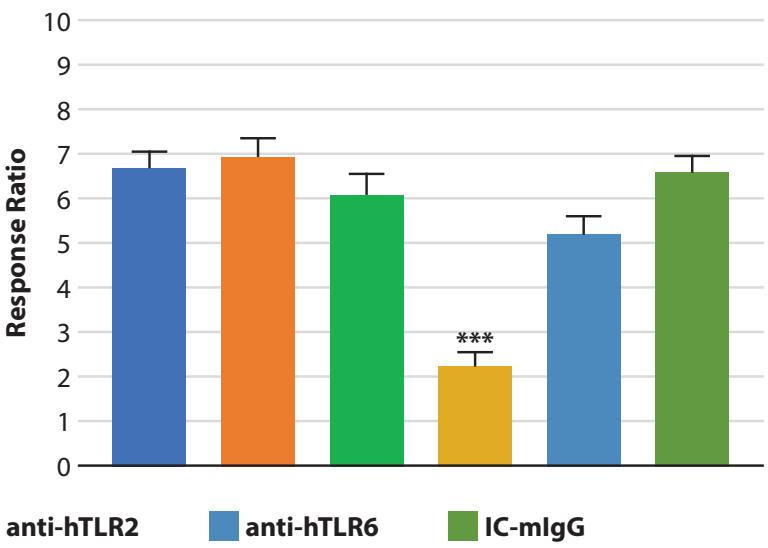

Figure 1. Response ratios of HEK-Blue $\mathrm{e}^{\mathrm{m}}-\mathrm{hTLR} 2$ cells to hypha and zoospore at various m.o.i.

The HEK-Null1 was used as negative control. Statistical significant difference between the stimulated HEK-Blue ${ }^{\mathrm{mm}}$-hTLR2 cells and HEK-Blue $\mathrm{e}^{\mathrm{tw}}$-hTLR2 cells stimulated with its negative control hypha or zoospore $(\mathrm{Nc})$ was determined (upper panel). Blocking stimulated HEK-Blue $e^{\text {mix }}$-hTLR2 cells with anti-hTLR1, 2, 6 or isotype control (IC) antibody (Ab) is showed in lower panel. HEK-Blue $e^{\text {mix }}$ hTLR2 cells were pre-incubated with $2.5 \mu \mathrm{g} / \mathrm{ml}$ of neutralizing (anti-hTLR1-IgG, anti-hTLR2-IgA, anti-hTLR6-IgG) or IC (IgG or $\operatorname{IgA} \mathrm{Ab}$ for $1 \mathrm{~h}$ before stimulation with hypha at m.o.i. of 0.17 or zoospore at m.o.i. of 0.04 . Statistical significant difference between TLR-blocking stimulated HEK-Blue ${ }^{\text {mm }}$-hTLR2 cells and IC or without antibody was determined. Response ratio was calculated from subtraction of stimulated cell response with unstimulated cell response. These data are the average from three independent experiments $\left({ }^{* *} p<0.01,{ }^{* *} p<0.001\right.$ and ns is no significant difference). Nc, process control, was prepared using the same process for fungal preparation without $P$. insidiosum inoculation.

\section{Characterization of TLR1-10 expressions in PHCEC}

TLR gene expression in PHCEC was shown in Table 2. Most patients expressed all of TLR1-10. However, differences in TLR expression were observed in some patients.

\section{Live P. insidiosum induced pro-inflammatory cytokine expres-} sion on PHCECs and HCECs at the early stage of infection

In order to determine the innate immune response at the early stage of infection, zoospore, the infective stage, was used to stimulate PHCECs. The expression levels of pro-inflammatory cytokines ( $I L-6, I L-8$ and $I L-1 \beta)$ were determined. Stimulation with live zoospores at the m.o.i. of 0.0025 significantly induced $I L-6$ and $I L-8$ expressions in PHCECs at 6 h. At m.o.i. of 0.005 , the $I L-6$ and $I L-8$ expressions were significantly upregulated at both 3 and $6 \mathrm{~h}$ after stimulation (Figure 2). Live zoospores at m.o.i. of 0.0025 and 0.005 significantly increased
IL-8 protein secretion (Figure 2) only at $6 \mathrm{~h}$. In contrast, live zoospores did not significantly induce $I L-1 \beta$ mRNA expression in PHCECs at both $3 \mathrm{~h}$ and $6 \mathrm{~h}$ (Figure 2). However, stimulation of PHCECs with killed zoospores or killed hyphae cannot induce any cytokine expressions (data not shown). These results indicated that live zoospore of $P$. insidiosum induced $I L-6$ and $I L-8$ but not $I L-1 \beta$ mRNA expressions in PHCECs at early stage of infection.

Stimulation of HCECs with live zoospores at the m.o.i. of 0.0025 could significantly induced $I L-6$ and $I L-8$ mRNA expressions at $6 \mathrm{~h}$. At m.o.i. of $0.005, I L-6$ and $I L-8$ mRNA expressions were significantly upregulated at both $3 \mathrm{~h}$ and $6 \mathrm{~h}$. (Figure 3a). Stimulation of HCECs with live zoospores did not significantly induce $I L-1 \beta$ mRNA expression at $3 \mathrm{~h}$ and 6 h (Figure 3b). 
Table 2. TLR gene expressions on PHCECs derived from corneal limbal tissue determined by RT-PCR.

\begin{tabular}{|c|c|c|c|c|c|c|c|c|c|c|}
\hline \multirow{2}{*}{ Sample No. } & \multicolumn{10}{|c|}{$T L R$ expressions } \\
\hline & 1 & 2 & 3 & 4 & 5 & 6 & 7 & 8 & 9 & 10 \\
\hline 1 & + & + & + & - & + & + & + & + & + & + \\
\hline 2 & + & + & + & + & + & + & + & - & + & + \\
\hline 3 & + & + & + & + & + & + & + & + & + & + \\
\hline 4 & + & + & + & + & + & + & + & - & + & + \\
\hline 5 & - & + & + & - & + & + & + & + & + & + \\
\hline 6 & - & + & + & - & + & + & + & + & + & + \\
\hline 7 & - & - & + & - & + & + & + & + & + & + \\
\hline 8 & + & + & + & - & + & + & + & + & + & + \\
\hline 9 & + & + & + & + & + & + & + & + & + & + \\
\hline 10 & + & + & + & - & + & + & + & - & + & + \\
\hline 11 & + & + & + & - & + & + & + & + & + & + \\
\hline 12 & - & + & + & - & + & + & + & + & + & + \\
\hline 13 & + & + & + & + & + & + & + & - & + & + \\
\hline 14 & + & + & + & + & + & + & - & - & + & + \\
\hline 15 & + & + & + & + & + & + & + & - & + & + \\
\hline
\end{tabular}
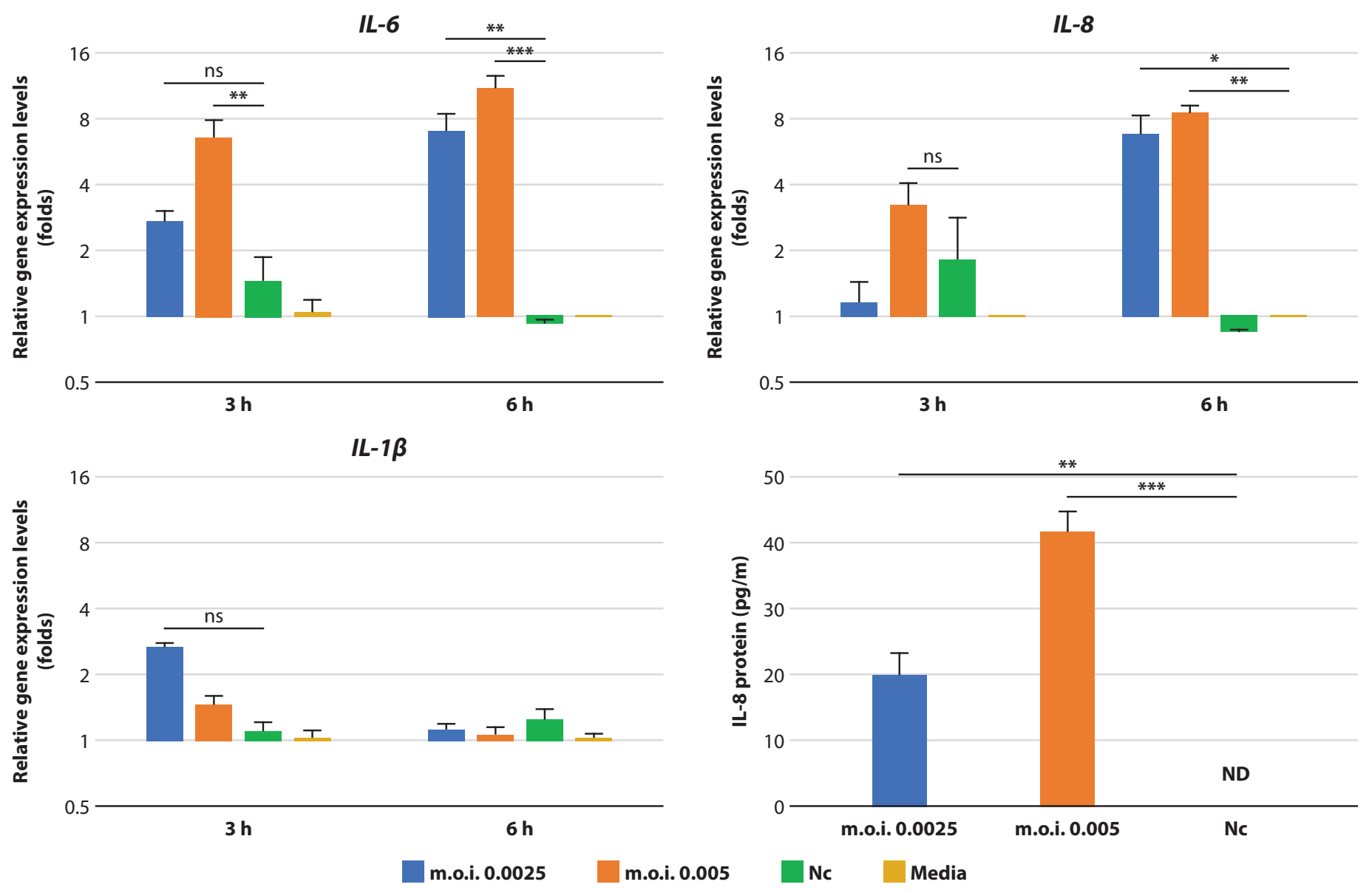

Figure 2. The early inflammatory cytokine production of PHCECs stimulated with live zoospore.

The gene expressions of $I L-6, I L-8$, and $I L-1 \beta$ were determined at m.o.i. of 0.0025 and 0.005 for 3 and 6 h using qRT-PCR. The $I L-8$ protein secretion was determined using ELISA at $6 \mathrm{~h}$ after stimulation. Statistical significant difference of relative gene expression levels $\left(\mathrm{ddC}_{\mathrm{T}}\right)$ of the stimulated PHCECs and PHCECs with its negative control zoospore $(\mathrm{Nc})$ was determined. Data are from three independent experiments $\left({ }^{*} p<0.05,{ }^{* *} p<0.01,{ }^{* *} p<0.001\right.$, ns is no significant difference and ND is not detected). $\mathrm{Nc}$, process control, was prepared using the same process for fungal preparation without $P$. insidiosum inoculation. 

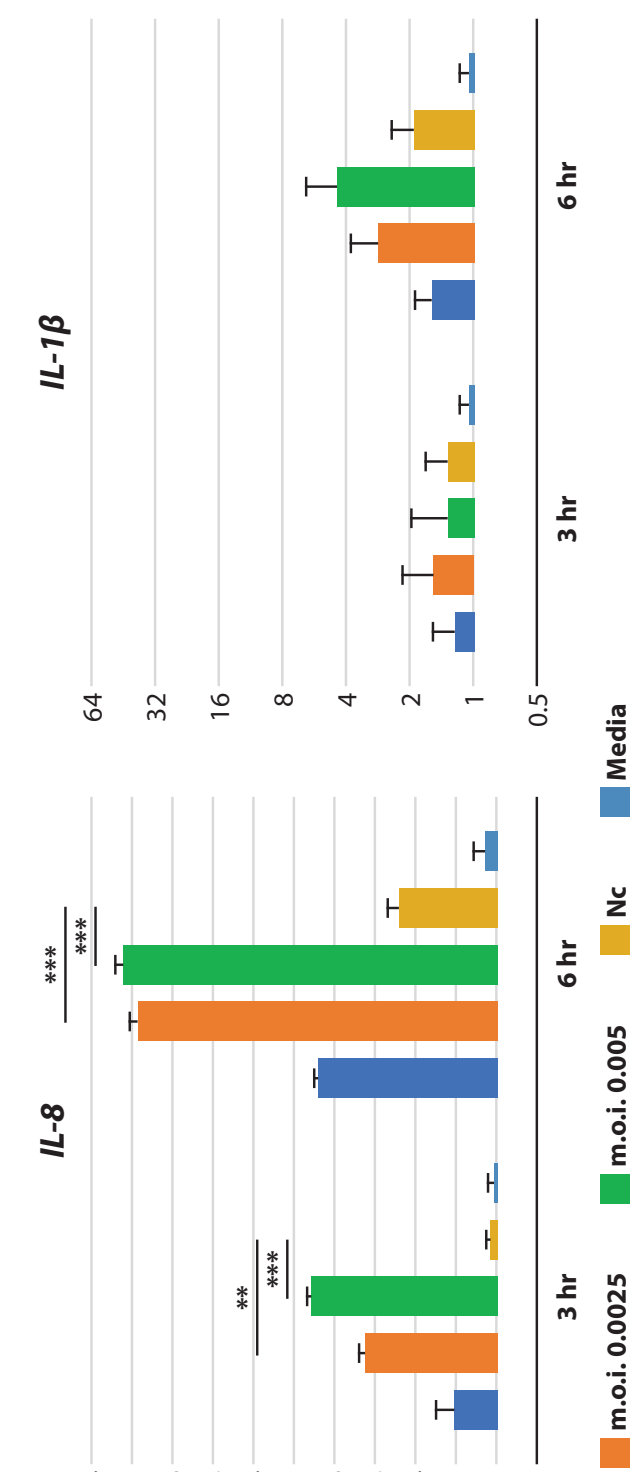

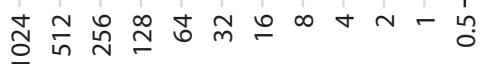

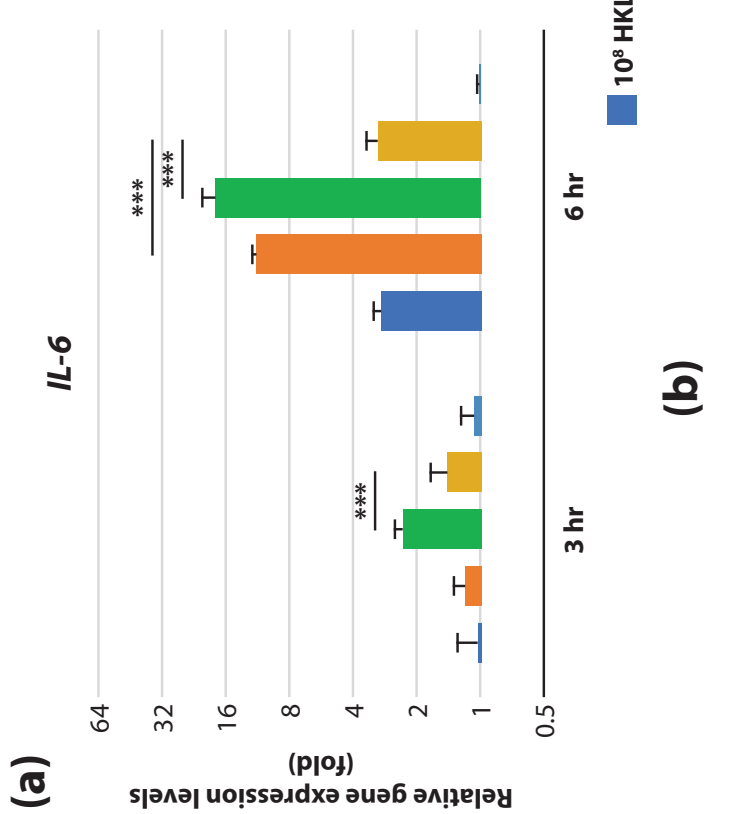

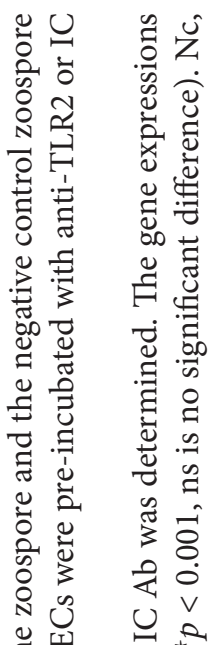

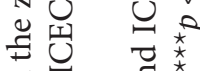

气|

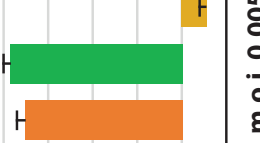

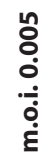

$\stackrel{\wp}{=}$

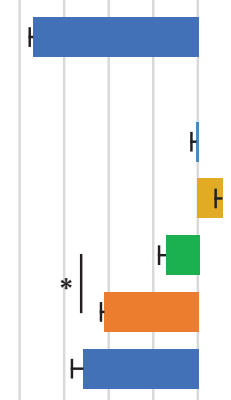

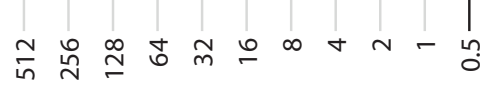

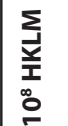

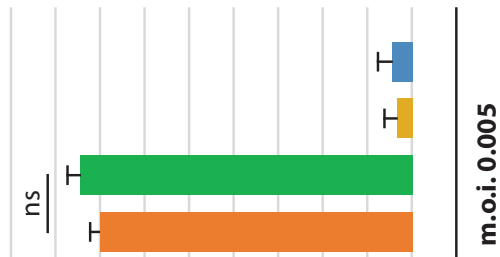

$\tilde{n}$

(p|이)

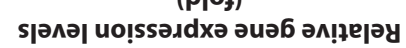

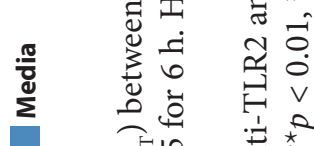

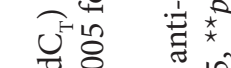

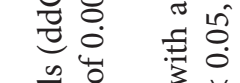

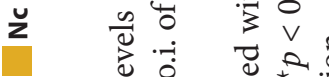

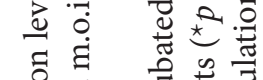

๙ के ब

范

०० 0 क्ष

a

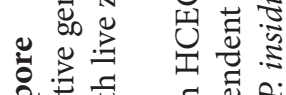

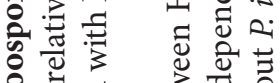

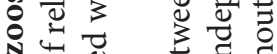

○

है



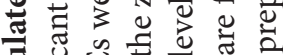

븨

के



啳

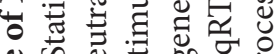

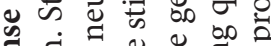

ปี่

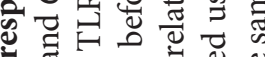



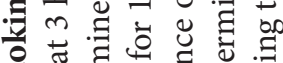

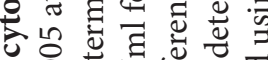

웜

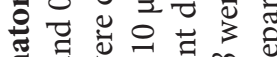

औ

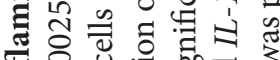

过

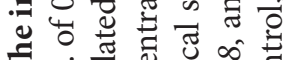

F.

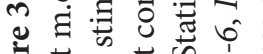



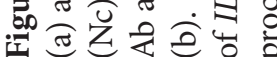


(a)



P. insidiosum zoospore



(b)

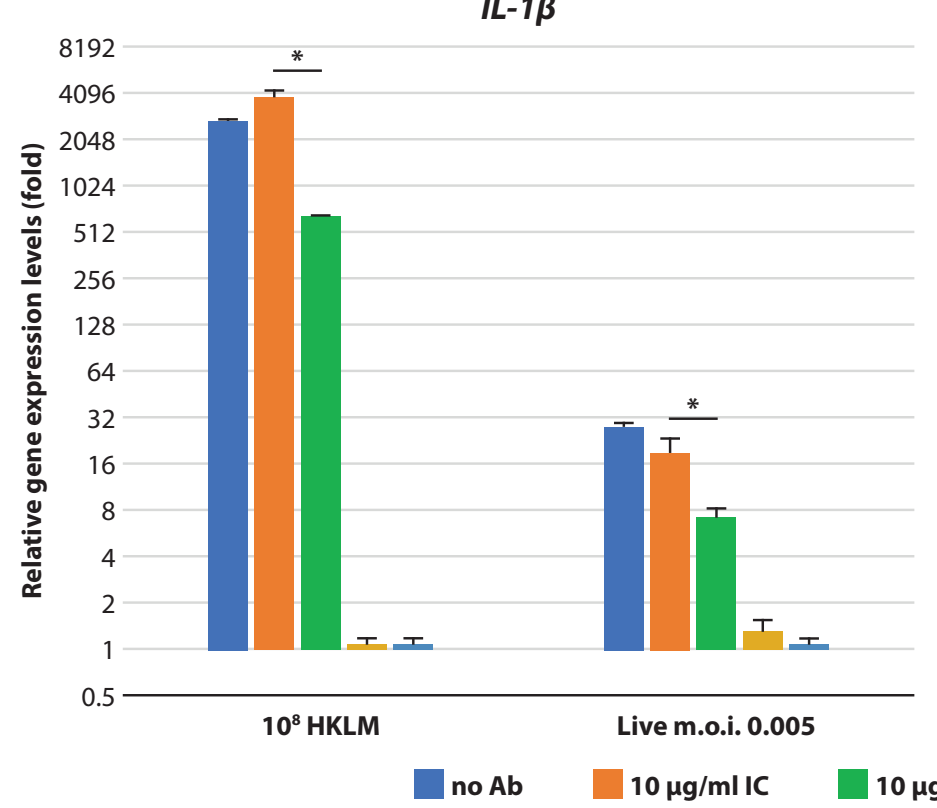



Figure 4. The cytokine mRNA expressions of MDMs from 5 healthy donors stimulated with $10^{8}$ HKLM or live zoospores at m.o.i. of 0.005 for $6 \mathrm{~h}$.

The data showed the difference of relative gene expression levels $\left(\mathrm{ddC}_{\mathrm{T}}\right)(\mathrm{a})$. Relative gene expression level is the gene expression of stimulated MDMs which substracted with unstimulated MDMs. The $I L-1 \beta$ and $I L-6$ mRNA (b) and IL-8 protein (c) expressions of the TLR2 neutralized MDMs were determined. MDMs were pre-incubated with anti-TLR2 or IC Ab at concentration of $10 \mu \mathrm{g} / \mathrm{ml}$ for $1 \mathrm{~h}$ before stimulation with $10^{8} \mathrm{HKLM}$ or live zoospores at m.o.i. of 0.005 for $6 \mathrm{~h}$. The cytokine mRNA expressions were determined using qRT-PCR. The IL-8 protein secretion from 3 healthy donors was determined using ELISA. Statistical significant difference of relative gene expression levels $\left(\mathrm{ddC}_{\mathrm{T}}\right)$ or protein concentration $(\mathrm{pg} / \mathrm{ml})$ between MDMs pre-incubated with anti-TLR2 and IC Ab were analyzed. The experiments were performed in three independent experiments $\left({ }^{*} p<0.05,{ }^{* *} p<0.01\right.$, ns is no significant difference). Nc, process control, was prepared using the same process for fungal preparation without $P$. insidiosum inoculation. 
(c)

Donor 1

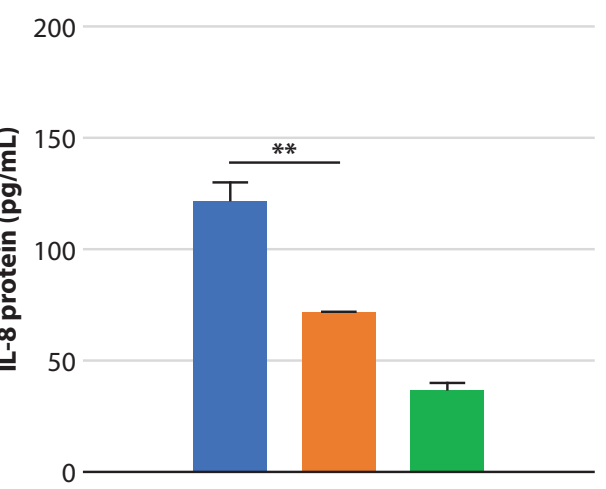

Donor 2

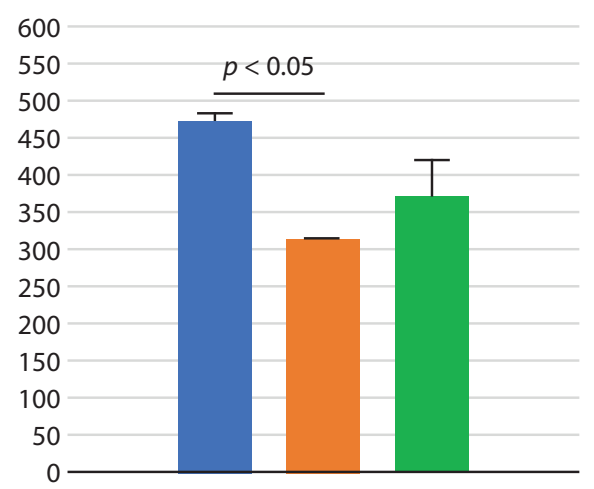

Donor 3

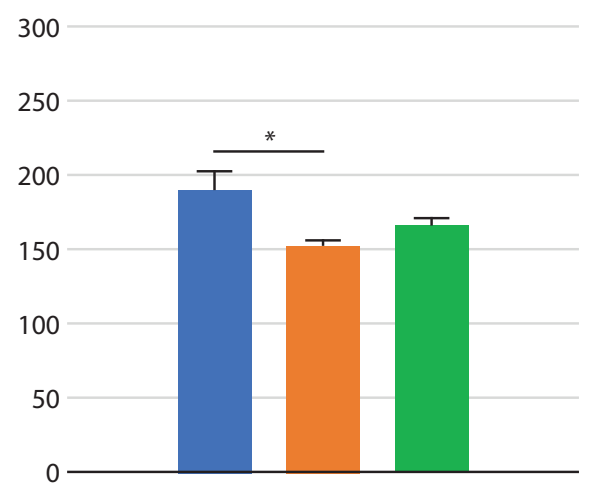

m.o.i. $0.005 / I C$

m.o.i. 0.005/aTLR2

Nc

In conclusion, similar to PHCECs, live but not killed zoospores (data not shown) of $P$. insidiosum induced $I L-6$ and $I L-8$ but not $I L-1 \beta$ mRNA expressions on HCECs at early stage of infection. Because of the limitation of primary cell preparation, HCECs were used to determine the role of TLR2 in next experiment.

\section{Live P. insidiosum induced pro-inflammatory cytokine expres- sion on HCECs through TLR2-independent pathway}

The blockade of TLR2 was used to determine the role of TLR2 to $I L-8$ and $I L-6$ mRNA expressions in HCECs. $I L-8$ and $I L-6$ expressions in the TLR2-blocked HCECs were compared with the cells blocked with the isotype control antibody and the unblocked cells. The results showed that the blockade of TLR2 on live zoospore-stimulated HCECs did not inhibit $I L-8$ and $I L-6$ mRNA expressions (Figure 3b). These results indicated that TLR2 did not play a major role in the induction of these cytokines at early stage of HCECs in response to live $P$. insidiosum infection.

\section{Live P. insidiosum induced pro-inflammatory cytokine expres- sion on MDMs}

In order to determine the role of TLR2 in induction of pro -inflammatory cytokine expressions in other cell types, MDMs from 5 healthy individuals were used in this experiment. Stimulation of MDMs with live zoospores induced $I L-6$ mRNA expression in 4 of 5 donors and induced $I L-1 \beta$ mRNA expression in all donors after $6 \mathrm{~h}$ of stimulation (Figure 4c). However, mRNA expression of $I L-8$ was not upregulated in 4 of 5 donors. These results suggested that live zoospore of $P$. insidiosum induces pro-inflammatory cytokine expressions in MDMs at the early stage of infection. However, there are some variations in individual subjects.

\section{Live P. insidiosum induced pro-inflammatory cytokine expres- sion on human MDMs through TLR2-dependent pathway}

The TLR2 blockade was done to confirm the role of TLR2 in induction of pro-inflammatory cytokine expressions in MDMs. The results showed that blockade of TLR2 significantly inhibit the expression of $I L-1 \beta$ mRNA after stimulated with live zoospores (Figure $4 \mathbf{b}$ ). Furthermore, the secretion of IL-8 protein was significantly decreased in TLR2 blockade MDMs. These results indicated that TLR2 involved in the induction of $I L-1 \beta$ mRNA expression and secretion of IL- 8 protein in MDMs at the early stage of live $P$. insidiosum infection.

\section{Discussion}

$P$. insidiosum is the causative agent of $P$. insidiosum keratitis or corneal ulcer., ${ }^{1,49-11}$ The innate immunity at the ocular surface, especially in the corneal epithelium, plays an important role in defense against pathogen infection due to their lack of lymphatic drainage and presence of blood ocular barrier. Currently, the responsive mechanisms to invasive pathogens are unclear. However, the mechanisms including productions of inflammatory cytokines, chemokines, antimicrobial peptides as well as recruitment of innate immune cells to the site of infection have been reported., ${ }^{5} 6$ TLR is an important receptor in the innate immune response to fungal infection and initiation of adaptive immunity. ${ }^{12,13}$ TLR1-10 are expressed in human corneal epithelial cells. ${ }^{5,6}$ The TLR-mediated innate immune response of corneal epithelium involves protective immune response through induction of human beta defensin (hBD) expression and promotes local inflammation by induction of pro-inflammatory cytokine expression. ${ }^{14,15}$

In the present study, we used HEK-Blue ${ }^{\text {Tim }}$-hTLR2 cells and found that both forms of $P$. insidiosum, zoospore and hypha, induced NF- $\kappa B$ activation through TLR2/2 homodimer but not TLR4 (data not shown). Our result correlates to several studies in the TLR2-mediated innate immune response to several fungal infections such as yeast zymosan, C. albicans, A. fumigates. ${ }^{16}$

Fungal cell wall components including mannan, phopolipomannan and glucuroxylomannan are ligands of TLR2. ${ }^{17}$ To date, the cell wall compositions of $P$. insidiosum have not been addressed. In the genus of Pythium, the hypha wall is composed of $80-90 \%$ of polysaccharide mainly $\beta$-glucans and cellulose. The cell wall of the mycelium of $P$. aphanidermatum comprise $18 \%$ of cellulose and $82 \%$ of $(1 \rightarrow 3),(1 \rightarrow 6)$ - $\beta$-d-glucans. $^{18}$ The $\beta$-1, 3-linked, $\beta$-1, 4-linked and $\beta$-1, 6-linked branching glucan are the cell wall component of $P$. debaryanum. ${ }^{19}$ In 1993, Cherif M. et al found the presence of chitin in P. ultimum cell wall. ${ }^{20}$ Therefore, the $\beta$-glucans and cellulose 
may be the putative ligands of PRRs. However, the identification of the P. insidiosum cell wall component and potential PRR ligands should be further studied.

Similar pattern to other live fungi, ${ }^{20-23}$ only live $P$. insidiosum, but not killed $P$. insidiosum (data not shown) significantly induce $I L-6$, and $I L-8$ mRNA and IL-8 protein secretion in both human primary and corneal epithelium cell line. Live and killed microorganisms can induce different immune response depending on their virulent factors. Live microorganisms can penetrate into the cell and secrete some effector molecules, which induce inflammation. ${ }^{24-26}$ The unresponsiveness of human corneal epithelium to killed hyphae of $P$. insidiosum might be caused by the loss of some virulent factors especially secretory components. The studies in dead bacteria also showed lower inflammatory stimuli compared to live pathogenic bacteria or T3SS expressing bacteria. ${ }^{6}$ Jin et al, found that HCECs respond to inactive hyphae of $F$. solani by upregulation of TLR2, 3, 4 and 6 as well as release of $I L-6$ and $I L-8 .{ }^{27}$ We used killed hyphae at the m.o.i. of 0.1 and this m.o.i. of fungus could not induce pro-inflammatory cytokine expressions on HCECs. Thus, using live zoospores as a model to study the innate immune response to $P$. insidiosum is more suitable for understanding the immune response or pathogenesis of $P$. insidiosum infection. In the experiments, after live zoospores were inoculated, they generate germ tube and become hypha form. Therefore, the cytokine responses were induced by both zoospore and hypha forms of P. insidiosum. In addition, the study of the different components or PAMPs between live and killed $P$. insidiosum is still required.

The pathogenesis of $P$. insidiosum keratitis may be resulted from human corneal epithelium response at the early stage of infection. The expression of $I L-6$ transcript and production of IL-8 protein may involve in acute phase response, recruitment and activation of neutrophils. Neutrophils and other polymorphonuclear leukocytes (PMNs) migrate into infected cornea to eliminate fungal pathogen by releasing the toxic substance leading to corneal destruction. The study of $A$. $f u$ migatus keratitis in rat model demonstrated that high severe score of cornea is resulted from influx of PMNs, upregulation of TLR2 and TLR4 expressions and over production of pro-inflammatory cytokines. ${ }^{22}$ The inhibition of TLR2 can attenuate corneal inflammation and prevent $A$. fumigatus invasion. ${ }^{20}$

Human macrophage may participate in vascular and (sub) cutaneous pythiosis. The vascular pythiosis patients usually presented with fever, skin ulcer, cellulitis, and chronic arterial inflammation. Human macrophage may facilitate the recruitment of neutrophil or eosinophil and enhance the inflammation as well. In the present study, we provide the first evident that live zoospore of $P$. insidiosum induces $I L-6, I L-1 \beta$ mRNA and IL- 8 protein productions in MDMs at the early stage of infection. The blockade of TLR2 on MDMs significantly decreased $I L-1 \beta$ mRNA expression and IL- 8 protein secretion. This finding indicating that $P$. insidiosum contains TLR2 ligand on its surface and be recognized by MDMs mediated inflammatory cytokine induction.
The TLR2 blockade MDMs stimulated with live zoospore significantly decrease only in the productions of $I L-1 \beta$ mRNA, and IL-8 protein. Other PRRs may be involved in cytokine productions. ${ }^{25,28}$ Furthermore, blockade of TLR2 did not completely, but majorly, inhibit the expressions of those pro-inflammatory cytokines in response to $P$. insidiosum infections. Therefore, the further studies of $P$. insidiosum recognition via other PRRs are interested for better understanding in host response to $P$. insidiosum infection.

This study provides the understanding in human corneal epithelial and macrophage response to $P$. insidiosum infection by production of inflammatory cytokines at the early stage of infection. The PAMPs or virulence factor found only in live $P$. insidiosum have the effect on induction of pro-inflammatory cytokine expression in corneal epithelium. Other PRRs such as intracellular nucleotide-binding oligomerization domaincontaining protein (NOD)-like receptors; NOD1 and C-type lectin receptor, ${ }^{16,29,30}$ which had been reported in other fungal keratitis, may cooperate with TLR2 in the induction of proinflammatory cytokine expression and be involved in pathogenesis of $P$. insidiosum keratitis. In contrast, TLR2 is involved in the induction of cytokines in P. insidiosum infected MDM. The activation of TLR2 on HEK-hTLR2 cell and the cytokine reduction in TLR2-blockade MDM indicating that $P$. insidiosum contains TLR2 ligand. Unrecognizing TLR2-mediated cytokine expression in corneal epithelium may due to the different and specificity of each cell type in distinguished the cellular response during infection. The knowledge of prominent factors of innate immune and inflammatory response in human corneal epithelium against $P$. insidiosum might be a potential novel therapeutic target for the treatment of the fungal keratitis.

\section{Conclusion}

This study focuses on the production of pro-inflammatory cytokines at early stage of infection in vitro. It provides better understanding of innate immune response of human corneal epithelial cell against $P$. insidiosum infection. The pathogen associated molecular patterns (PAMPs) or virulence factors found only in live $P$. insidiosum affect the induction of proinflammatory cytokine expression and may cause pathological effects.

The symptoms of $P$. insidiosum keratitis include corneal ulcer, dense stromal infiltration, increased stromal necrosis, endothelial plaque and high intraocular pressure. In present study, we found that both zoospore and hypha form of $P$. insidiosum can be recognized by TLR $2 / 2$ homodimer in HEKBlue $^{\mathrm{Tm}}-\mathrm{hTLR}$ cells leading to NF- $\kappa \mathrm{B}$ activation. The induction of TLR2-dependent NF- $\kappa \mathrm{B}$ activation by $P$. insidiosum was dose-dependent. The human corneal epithelium responded to live $P$. insidiosum infection through the expressions of $I L-6$, $I L-8$, but not $I L-1 \beta$ during early stage of infection. However, stimulation of human corneal epithelium with killed $P$. insidiosum did not induce the expression of the pro-inflammatory cytokines. The expressions of $I L-6$ and $I L-8$ in $P$. insidiosum infected human corneal epithelium were not dependent only on TLR2 recognition. However, the expressions of pro-inflammatory cytokine genes during early stage of $P$. insidiosum infection 
may promote the recruitment of PMNs and facilitate local inflammation contributing to pathogenesis of $P$. insidiosum keratitis. This study is the first report of human corneal epithelium in response to $P$. insidiosum infection as well as the involvement of TLR2.

\section{References}

1. Krajaejun T, Sathapatayavongs B, Pracharktam R, Nitiyanant P, Leelachaikul P, Wanachiwanawin W, et al. Clinical and Epidemiological Analyses of Human Pythiosis in Thailand. Clin Infect Dis. 2006;43:569-76.

2. Gaastra W, Lipman LJA, De Cock AWAM, Exel TK, Pegge RBG, Scheurwater J, et al. Pythium insidiosum: An overview. Vet Microbiol. 2010;146:1-16.

3. Lelievre L, Borderie V, Garcia-Hermoso D, Brignier AC, Sterkers M, Chaumeil C, et al. Imported Pythium insidiosum Keratitis After a Swim in Thailand by a Contact Lens-Wearing Traveler. Am J Trop Med Hyg. 2015;92:270-3.

4. Tanhehco TY, Stacy RC, Mendoza L, Durand ML, Jakobiec FA, Colby KA. Pythium insidiosum keratitis in Israel. Eye contact lens. 2011;37:96-8.

5. Ueta M, Kinoshita S. Innate immunity of the ocular surface. Brain Research Bulletin. 2010;81:219-28.

6. Pearlman E, Sun Y, Roy S, Karmakar M, Hise AG, Szczotka-Flynn L, et al. Host Defense at the Ocular Surface. Int Rev Immunol. 2013;32:4-18.

7. Johnson AC, Heinzel FP, Diaconu E, Sun Y, Hise AG, Golenbock D, et al. Activation of Toll-Like Receptor (TLR)2, TLR4, and TLR9 in the Mammalian Cornea Induces MyD88-Dependent Corneal Inflammation. Invest Ophthalmol Vis Sci. 2005;46:589-95.

8. Chaiprasert A, Samerpitak K, Wanachiwanawin W, Thasnakorn P. Induction of zoospore formation in Thai isolates of Pythium insidiosum. Mycoses. 1990;33:317-23.

9. Badenoch PR, Mills RAD, Chang JH, Sadlon TA, Klebe S, Coster DJ. Pythium insidiosum keratitis in an Australian child. Clin Exp Ophthalmol. 2009;37:806-9.

10. Lekhanont K, Chuckpaiwong V, Chongtrakool P, Aroonroch R, Vongthongsri A. Pythium insidiosum keratitis in contact lens wear: a case report. Cornea. 2009;28:1173-7.

11. Murdoch D, Parr D. Pythium insidiosum keratitis. Aust N Z J Ophthalmol. 1997;25:177-9.

12. Wüthrich M, Deepe GS, Klein B. Adaptive Immunity to Fungi. Ann Rev Immunol. 2012;30:115-48

13. Romani L. Immunity to fungal infections. Nat Rev Immunol. 2011;11: 275-88.

14. Wu M, McClellan SA, Barrett RP, Hazlett LD. $\beta$-Defensin-2 Promotes Resistance against Infection with $P$. aeruginosa. J Immunol. 2009;182: 1609-16.

15. Kumar A, Zhang J, Yu F-SX. Toll-like receptor 2-mediated expression of $\beta$-defensin-2 in human corneal epithelial cells. Microbes Infect. 2006;8: 380-9.

16. Kaur A, Kumar V, Singh S, Singh J, Upadhyay N, Datta S, et al. Toll-like receptor-associated keratitis and strategies for its management. 3 Biotech. 2015;5:611-9.

17. Brown GD. Innate antifungal immunity: the key role of phagocytes. Annu Rev Immunol. 2011;29:1-21.
18. Blaschek W, Käsbauer J, Kraus J, Franz G. Pythium aphanidermatum: culture, cell-wall composition, and isolation and structure of antitumour storage and solubilised cell-wall $(1 \rightarrow 3),(1 \rightarrow 6)$ - $\beta$-d-glucans. Carbohyd Res. 1992;231:293-307.

19. Yamada M, Miyazaki T. Ultrastructure and Chemical Analysis of the Cell Wall of Pythium debaryanum1. Jpn J Microbiol. 1976;20:83-91.

20. Guo H, Gao J, Wu X. Toll-like receptor 2 siRNA suppresses corneal inflammation and attenuates Aspergillus fumigatus keratitis in rats. Immunol cell biol. 2012;90:352-7.

21. Che CY, Jia WY, Xu Q, Li N, Hu LT, Jiang N, et al. The roles of surfactant protein D during Aspergillus fumigatus infection in human corneal epithelial cells. Int J Ophthalmol. 2012;5:13-7.

22. Jie Zhao, Wu Xy, Yu FSX. Activation of Toll-like receptors 2 and 4 in Aspergillus fumigatus keratitis. Innate Immun. 2009;15:155-68.

23. Guo $\mathrm{H}, \mathrm{Wu} \mathrm{X}$. Innate responses of corneal epithelial cells against Aspergillus fumigatus challenge. FEMS Immunol Med Microbiol. 2009;56:88-93.

24. Jin X, Qin Q, Tu L, Zhou X, Lin Y, Qu J. Toll-like receptors (TLRs) expression and function in response to inactivate hyphae of Fusarium solani in immortalized human corneal epithelial cells. Molec Vis. 2007;13: 1953-61.

25. Karthikeyan RS, Leal SM, Prajna NV, Dharmalingam K, Geiser DM, Pearlman E, et al. Expression of Innate and Adaptive Immune Mediators in Human Corneal Tissue Infected With Aspergillus or Fusarium. J Infect Dis. 2011;204:942-50.

26. Kumar A, Zhang J, Yu FSX. Innate Immune Response of Corneal Epithelial Cells to Staphylococcus aureus Infection: Role of Peptidoglycan in Stimulating Proinflammatory Cytokine Secretion. Invest Ophthalmol Vis Sci. 2004;45:3513-22.

27. Wu PZJ, Zhu H, Thakur A, Willcox MDP. Comparison of potential pathogenic traits of staphylococci that may contribute to corneal ulceration and inflammation. Aust N Z J Ophthalmol. 1999;27:234-6.

28. Leal SM Jr, Cowden S, Hsia YC, Ghannoum MA, Momany M, Pearlman E. Distinct Roles for Dectin-1 and TLR4 in the Pathogenesis of Aspergillus fumigatus Keratitis. PLoS Pathog. 2010;6:e1000976.

29. Zhang Y, Wu J, Xin Z, Wu X. Aspergillus fumigatus triggers innate immune response via NOD1 signaling in human corneal epithelial cells. Exp Eye Res. 2014;127:170-8.

30. Wanachiwanawin W, Mendoza L, Visuthisakchai S, Mutsikapan P, Sathapatayavongs B, Chaiprasert A, et al. Efficacy of immunotherapy using antigens of Pythium insidiosum in the treatment of vascular pythiosis in humans. Vaccine. 2004;22:3613-21.

31. de Oliviera Nascimento L, Massari P, Wetzler LM. The Role of TLR2 in Infection and Immunity. Front Immunol. 2012;3:79-95.

32. Tantibhedhyangkul W, Ben Amara A, Textoris J, Gorvel L, Ghigo E, Capo C, et al. Orientia tsutsugamushi, the causative agent of scrub typhus, induces an inflammatory program in human macrophages. Microb Pathog. 2013;55:55-63.

33. Prabhasawat P, Ekpo P, Uiprasertkul M, Chotikavanich S, Tesavibul N. Efficacy of cultivated corneal epithelial stem cells for ocular surface reconstruction. Clin Ophthalmol. 2012;6:1483-92.

34. Inthasin N, Wongprompitak P, Boonwong C, Ekpo P. Toll-like receptor 2 mediates induction of human beta-defensin 2 by Leptospira interrogans in oral mucosal epithelial cells. Asian Pac J Allergy and Immunol. Forthcoming 2018. 